\title{
Role of biomarkers for early detection of lung cancer and chemoprevention
}

\author{
F.R. Hirsch*, D.T. Merrick*,\#, W.A. Franklin*
}

Role of biomarkers for early detection of lung cancer and chemoprevention. F.R. Hirsch, D.T. Merrick, W. A. Franklin. C ERS Journals Ltd 2002.

ABSTRACT: Lung cancer is the leading cause of cancer deaths in developed countries. The poor prognosis associated with this disease is closely related to the fact that most lung cancer patients are not identified until their malignancy has reached an advanced stage.

Recent advances have added to the understanding of the morphological and molecular characteristics of preinvasive bronchial lesions and early lung cancers. Such information is being used to provide new tests for the detection of lung cancer at early or preinvasive stages, and for identifying targets for therapeutic intervention that can prevent progression to advanced disease. Laser induced fluorescence endoscope bronchoscopy has improved the sensitivity with which preinvasive dysplastic bronchial lesions and early invasive malignancies can be detected. Morphological features of such lesions have been described and can be monitored by follow-up bronchoscopies in order to validate potential chemoprevention treatments.

Distinct morphological characteristics such as angiogenic squamous dysplasia also suggest that processes like angiogenesis are present early in the development of lung cancer. Furthermore, tissue obtained from these early lesions has been used to describe alterations in the expression of a number of factors that distinguish these early lesions from normal bronchial epithelium. This could provide molecular markers and targets for the detection and treatment of early lung cancer. Studies to detect these alterations by polymerase chain reaction and/or immunhistochemical analyses of easily obtained specimens such as sputa are helping identifing molecular markers that could be utilized in effective screening programmes.

The current article reviews new findings regarding the molecular biology of preinvasive bronchial lesions and early lung cancers, and describes new developments regarding their application in the early detection and chemoprevention of lung cancer. Eur Respir J 2002; 19: 1151-1158.
*Dept of Pathology, University of Colorado Health Sciences Centre and \#Dept of Pathology, Denver Veterans Administration Medical Centre, Denver, USA.

Correspondence: F.R. Hirsch, University of Colorado Cancer Center, Dept of Pathology, University of Colorado Health Sciences Center, 4200 East Ninth Avenue, B216, Denver, CO 80262. Fax: 3031511835

E-mail: Fred.Hirsch@UCHSC.edu

Keywords: Early detection

lung cancer

molecular biology

pathology

review

Received: November 82001

Accepted after revision January 23 2002

This study was supported by National Cancer Institute Grants CA 58187 from the Specialized Programme of Research Excellence (SPORE)-Lung and the Lung Cancer Biomarkers and Chemoprevention Consortium, by a Career Development Grant for F.R. Hirsch from The International Association for the Study of Lung Cancer/Cancer Research Foundation of America and by a seed grant from the Colorado SPORE-Lung Programme to D.T. Merrick.
Lung cancer is the leading cause of cancer deaths in the USA in both males and females [1]. The high mortality associated with this disease is primarily due to the fact that the majority of lung cancers are not detected until they have progressed to an advanced stage. More than two-thirds of lung cancers are associated with lymph-node metastases at the time of diagnosis [2]. The 5-yr survival of patients with clinical stage II-IV disease is poor, ranging from $40 \%$ down to $5 \%$ [3]. In order to reduce the mortality associated with lung cancer, new techniques must be developed to diagnose and treat early invasive or preinvasive disease. The development of such tools could lead to the establishment of routine screening protocols in well-defined high-risk patient populations. Chest radiography and sputum cytology have

Previous articles in this series: No. 1: Steels E, Paesmans M, Berghmans T, et al. Role of p53 as a prognostic factor for survival in lung cancer: a systematic review of the literature with a meta-analysis. Eur Respir J 2001; 18: 705-719. No. 2: van Klaveren RJ, Habbema JDF, Pedersen JH, de Koning HJ, Oudkerk M, Hoogsteden HC. Lung cancer screening by low-dose spiral computed tomography. Eur Respir J 2001; 18: 857-866. No. 3: Brambilla E, Travis WD, Colby TV, Corrin B, Shimosato Y. The new World Health Organization classification of lung tumours. Eur Respir J 2001; 18: 1059-1068. No. 4: Brock CS, Lee SM. Anti-angiogenic strategies and vascular targeting in the treatment of lung cancer. Eur Respir J 2002; 19: 557-570. 
been the primary tools used for establishing diagnoses of lung cancer. In the 1970s several large clinical trials were performed to evaluate the efficacy of using these two methodologies together in lung cancer screening programmes [4-6]. Although both techniques have been demonstrated to identify malignancies well before lung cancer becomes clinically symptomatic [7, 8], the implementation of screening programmes using these testing modalities failed to show a reduction in lung cancer mortality in large clinical trials. To date, no lung cancer screening programme has been approved for general clinical application. While many have raised questions regarding the design and interpretation of these original clinical trials, the need to develop new techniques for early diagnosis and effective therapy is widely recognized.

Highly sensitive and specific tests for the early diagnosis of lung cancer and its precursor lesions are needed in order to establish effective lung cancer screening programmes. Furthermore, it is important to be able to perform these tests on easily obtained specimens in a cost-effective manner. Finally, effective new therapies will need to be developed to treat patients identified in the screening programmes. Recent work has begun to define the molecular characteristics of preneoplastic and early invasive bronchial lesions. In addition to providing an understanding of the biology of these early lesions, the information gathered through these efforts should allow for the development of new diagnostic and therapeutic strategies that will ultimately provide the tools needed to reduce the devastating toll associated with lung cancer. In this article new advances in the understanding of the biology of early lung cancer associated lesions will be reviewed and some of the promising new data regarding diagnosis and treatment of these lesions will be discussed.

\section{Biology of premalignant and early invasive bronchial lesions}

In recent years numerous studies have provided a wealth of information regarding the histological and molecular characteristics of premalignant changes in bronchial mucosa [9]. These various epithelial lesions are thought to represent a histological spectrum which is now included in the World Health Organization (WHO) classification of lung tumours (fig. 1). The earliest lesions include reserve cell hyperplasia and squamous metaplasia without associated cellular atypia/dysplasia. Because these lesions spontaneously regress with smoking cessation, they are believed to represent reactive changes rather than true premalignant lesions $[10,11]$. This view is supported by findings that show reserve cell hyperplasia and squamous metaplasia are not consistently associated with molecular alterations which distinguish them from normal bronchial epithelium and are frequently found in association with chronic inflammation. Conversely, low and high grade dysplasia and carcinoma in situ (CIS) are believed to be true premalignant lesions associated with increased risk for the development of lung carcinoma. While the degree of increased risk associated with low-grade dysplasias is unclear, the presence of high-grade dysplasia and CIS as identified in sputa or bronchial tissue have been demonstrated to be associated with a significant increased risk of subsequent development of lung cancer [12, 13]. In one study it was demonstrated that, depending on the degree of dysplasia (moderate versus severe), $10-40 \%$ of patients diagnosed with high-grade dysplasia in sputa specimens were observed to subsequently develop cancer in a period of up to 9 yrs following the diagnosis of dysplasia [12]. A study conducted by SACCOMAno et al. [7] involving multiple specimens a)

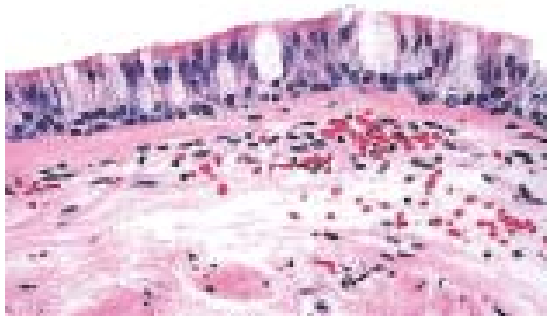

d)

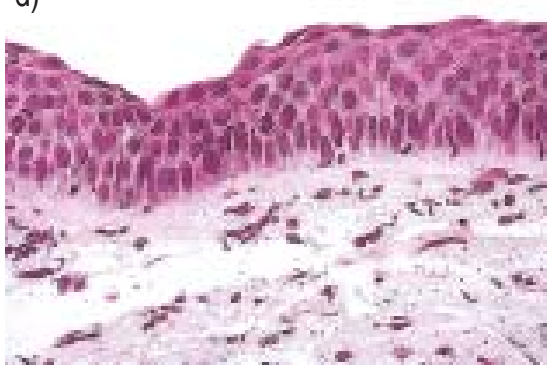

b)

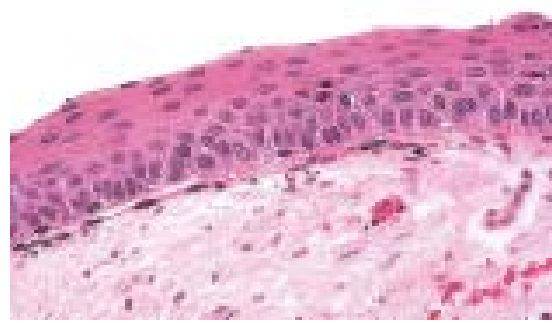

e)

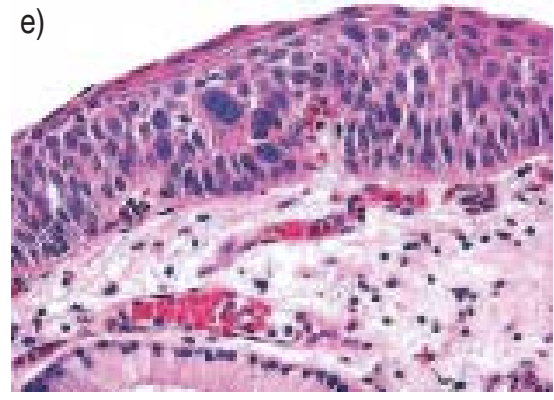

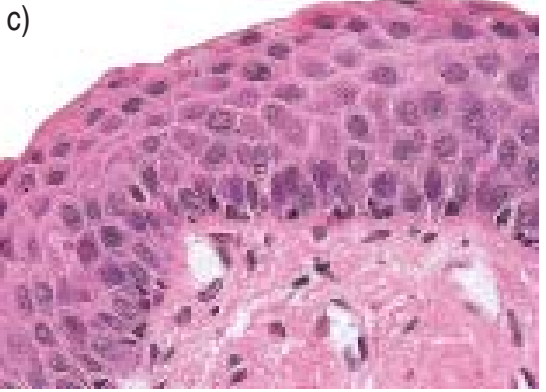

f)

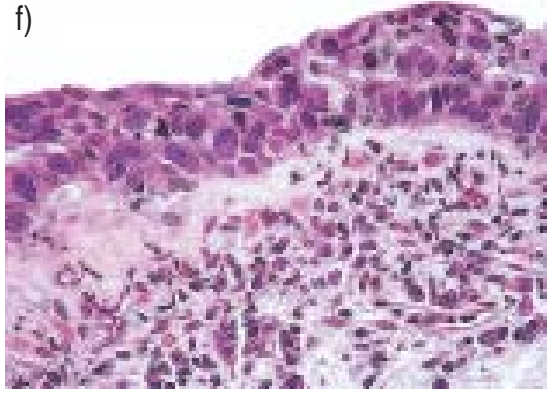

Fig. 1.-Grading of morphological changes in bronchial epithelium used for classification scheme applied in chemoprevention and other studies at the University of Colorado Cancer Centre. a) Normal (grade 1), b) squamous metaplasia (grade 2), c) mild dysplasia (grade 4), d) moderate dysplasia (grade 5), e) severe dysplasia (grade 6) and f) carcinoma in situ (grade 7). 
from 6,000 male patients demonstrated that cytologic atypia could be identified in sputum specimens an average of 4-5 yrs before the development of frank lung cancer. Another study showed that the majority of a small group of patients with biopsy-proven CIS subsequently developed invasive cancer [13]. In addition, the observation that high-grade dysplasia and CIS seldom regress even after smoking cessation further demonstrates the serious potential associated with these lesions [14].

Additional observations regarding histological characteristics and molecular alterations associated with these premalignant bronchial lesions also support their central role in the development of lung cancer. Angiogenic squamous dysplasia (ASD) is a term that has been introduced to describe a frequent histological feature seen in bronchial dysplasias $[15,16]$. ASDs demonstrate papillary vascular structures that protrude into overlying dysplastic bronchial epithelium, and these lesions have been demonstrated to be associated with an increase in the number of subepithelial microvascular structures as compared to normal bronchial epithelium [15]. Furthermore, immunohistochemical studies have shown expression of the angiogenic mediator vascular endothelial growth factor in dysplastic bronchial epithelium [17, 18]. Angiogenic activity is required for the growth of malignant tumours. Thus the demonstration of this activity in premalignant lesions of the airways further supports the malignant potential attributable to bronchial preneoplasia and could have significance in relation to the treatment of these lesions. Dysplastic lesions are found in the airways of most patients with lung cancer in both contiguous and remote sites in relation to the invasive cancer. Molecular studies comparing dysplasias and invasive cancers from the same resection specimen have also revealed evidence that supports the role of dysplasia as a precursor lesion in the development of invasive cancer. Many of the dysplastic lesions in these specimens display loss of heterozygosity $(\mathrm{LOH})$ in chromosomal sites that are identical to those found in the associated invasive cancer [19]. Similar mutations in the tumour suppressor gene, p53, can also be found in lung cancers and their corresponding dypslasias, however these concordant findings are much less frequent than those found in $\mathrm{LOH}$ analyses suggesting that p53 mutations may represent a later change in the progression to invasive cancer [19]. Such observations have also provided information pertinent to the understanding of the mechanisms by which lung cancer develops.

The development of invasive lung cancer is believed to involve two distinct but complimentary processes. Exposure of the lower airways to carcinogens in tobacco smoke leads to widespread cellular and molecular changes over broad mucosal expanses, a process first described in head and neck cancer [20] and referred to as "field cancerization". This process is associated with the stepwise accumulation of mutations and epigenetic alterations that lead to dysplasia and eventually to invasive carcinoma, a process referred to as "multistep carcinogenesis". Exposure of airway epithelium to repeated high doses of carcinogens in tobacco smoke may lead to the establishment of multiple lesions, each derived from a cell that has acquired unique mutations in comparison to other sites. This concept is supported by findings in a study of multiple primary lung tumours that demonstrated differences in the genetic alterations associated with each tumour [21]. Alternatively, it has been suggested that multiple airway epithelial lesions could be established from a single progenitor cell that has undergone mutation or epigenetic change and subsequent clonal expansion. In this model, cells derived from the original clone of altered cells establish new premalignant lesions at sites remote from the original site. The observation of identical p53 mutations in respiratory epithelium at widely dispersed sites within the airways of a lung cancer patient supports this concept [22]. These two hypotheses are not mutually exclusive and probably occur in combination. Regardless of the mechanism by which the premalignant lesions are established, the development of lung cancer would then follow via multistep carcinogenesis at the site in which the necessary type and number of additional genetic/molecular alterations occur.

Bronchial dysplasias are believed to be direct precursors of squamous cell carcinoma of the lung, however the role they might play, if any, in the development of other nonsmall cell and small cell lung carcinomas is unclear. In the case of adenocarcinoma, a separate lesion referred to as atypical adenomatous hyperplasia $(\mathrm{AAH})$ has been implicated as a precursor of these invasive glandular cancers. Studies have shown that AAH frequently demonstrates $\mathrm{LOH}$, aneuploidy, K-ras mutations and less frequent alterations of p53 expression similar to bronchial dysplasias $[23,24]$. Small peribronchiolar lesions demonstrating neuroendocrine features and dubbed neuroendocrine hyperplasias have been suspected to be precursor lesions of small cell carcinoma but have not been definitively associated with the subsequent development of small cell carcinoma at this point [25]. Finally, a lesion described as "respiratory bronchiolitis" many years ago by AuERBACH, et al. [10] was found with sufficient frequency to suggest a possible, but largely unexplored, role in lung carcinogenesis .

\section{Biomarkers of premalignant and early lung cancer lesions}

A number of molecular alterations have recently been identified in premalignant bronchial lesions and early lung cancer (table 1). Altered expression of oncogenes, tumour suppressor genes (TSG) and deoxyribonucleic acid (DNA) repair genes frequently found in established lung cancer are now being found in varying degrees in dysplastic and minimally invasive lung lesions also. In addition, structural alterations (i.e. deletions, promoter methylation, etc.) to these genes that distinguish malignant tissue from normal bronchial epithelium are frequently present in these early lesions. Full characterization of these alterations in early lung lesions is beginning to provide promising information regarding both the identification of biomarkers that could be used in lung cancer screening programmes and molecular pathways that 
Table 1.-Molecular alterations in various stages of bronchial carcinogenesis

\begin{tabular}{lc}
\hline Molecular alteration & Frequency \% \\
\hline Early changes $^{\#}$ & \\
3p LOH/small telomeric deletions & 80 \\
Microsatellite alterations & 50 \\
9p21 LOH & 70 \\
Telomerase dysregulation & 80 \\
MYC overexpression & 60 \\
Intermediate changes & \\
8p21-23 LOH & 80 \\
Neoangiogenesis & 40 \\
Loss of FHIT immunostaining & 40 \\
p53 LOH & 70 \\
Aneuploidy & 80 \\
Methylation & 100 \\
Late changes & \\
TP53 Mutations & 70 \\
5q21 APC-MCC LOH & 30 \\
K-ras mutation & 20 \\
\hline
\end{tabular}

LOH: loss of heterozygosity; FHIT: fragile histidine triad.

\#: found in normal hyperplastic and metaplastic epithelium in smokers; ${ }^{\top}$ : generally first detected in bronchial dysplasias; ${ }^{+}$: usually only found in carcinoma in situ and invasive carcinoma.

could be targeted in therpeutic interventions aimed at preventing the development or progression of lung cancer.

TSGs have been some of the first and most thoroughly studied genes as potential early markers of lung cancer. Mutations of the p53 gene are found in many lung cancers, and studies have shown that these mutations can be detected in some of the sputa samples from patients with p53 mutation positive cancers [26, 27]. However, since p53 mutations are absent in significant numbers of lung cancers, and these mutations can be detected in less than one-half of sputa samples from patients with these p53 mutation positive cancers, it appears that screening using these analyses would not be sufficiently sensitive. Interestingly, in comparison to the rate of detection of p53 mutations, immunohistochemical studies have shown a higher prevalence of p53 overexpression in biopsies of premalignant bronchial lesions [28]. A study by BRAMBILla et al. [29] has suggested that premalignant lesions associated with p53 overexpression are more likely to progress to invasive cancer than those that are not associated with overexpression. However, whether sensitive assays of p53 overexpression could be applied to screening specimens such as sputa remains to be determined. A broader genomic based assay of TSG alterations has been employed in $\mathrm{LOH}$ analyses of lung cancers and precursor lesions. These assays identify allelic loss of known and putative TSGs that are thought to contribute to the development of lung cancers when inactivation of the remaining allele occurs through processes such as mutation or hypermethylation in clones of cells in which there has been an initial LOH. Recent work by WistuBA et al. [30] has detected $22 \mathrm{LOH}$ hotspots in small cell lung carcinomas and nonsmall cell lung carciomas, many of which may be mutated in one-half or more of lung cancers. Furthermore, $\mathrm{LOH}$ at many of these sites can also be demonstrated in premalignant lesions [31-35]. However, because of the multiplicity of loci that are affected by $\mathrm{LOH}$ and the detection of $\mathrm{LOH}$ at very early stages of carcinogenesis, it is unlikely that $\mathrm{LOH}$ analysis will provide a practical screening tool. In addition to TSGs, overexpression of oncogenes, cell-cycle regulators and cell-proliferation markers such as c-myc and k-ras, cyclins D1 and E and MCM2 respectively have been described in both tumours and premalignant bronchial lesions [36-41]. Alterations in microsatellite markers have similarly been found in preinvasive and invasive lung lesions $[42,43]$. Taken alone, none of these markers show very high sensitivity with overall detection in tissue reaching only $60-70 \%$ at best. However, if used in combination an acceptable level of sensitivity in analyses of screening specimens such as sputa may be achievable.

Immunohistochemical analysis of sputum samples is a technique that is being investigated as a screening tool for potential application regarding the expression of early markers of lung cancer. One protein that has been studied extensively using this methodology is heterogeneous nuclear ribonucleoprotein A2/B1 (hnRNP A2/B1). Overexpression of this protein appears to be ubiquitous in lung tissue with squamous cell carcinoma and is also found in the majority of adenocarcinomas and other types of nonsmall cell carcinomas [44-46]. Studies applying this technique to sputa from patients with subsequently identified invasive lung cancer have demonstrated a 2-3-fold increase in sensitivity in detecting lung cancer as compared to standard sputum cytology or radiographical analysis [45, 47]. These hnRNP A2/B1 positive cells could be detected in the sputum on average 2 yrs before detectable radiographical and cytological changes were discovered in the patients. In addition, recent studies have shown that hnRNP B1 positive staining can be demonstrated in nearly two-thirds of bronchial biopsies showing histological changes of bronchial dysplasia [46]. Whether the hnRNP B1 positive dysplasias are associated with higher potential for progression to invasive carcinoma remains to be determined.

Polymerase chain reaction (PCR) analyses of sputa and other types of specimens that could be used in screening assays is another technique that shows great promise for application in the early diagnosis of lung cancer. This technique has been employed in the study of DNA promoter methylation status in lung cancer. Inactivation of genes implicated in the development of cancer by promoter hypermethylation is now recognized as a frequent event. A number of recent studies have identified numerous genes whose expression is altered in lung cancer due to methylation [48-51]. The growing list of genes whose expression in lung cancer appear to be affected by hypermethylation includes genes with a wide variety of functions such as p16, $\mathrm{p} 15$, retinoic acid receptor- $\beta$ (RAR- $\beta$ ), RASSF1, fragile histidine triad (FHIT), tissue inhibitor of metalloproteinase 3, O6-methylguanine-DNA-methyltransferase (MGMT), death-associated protein kinase, 
E-cadherin, p14 and glutathione S-transferase P1. Re-expression of some of these genes has been shown to inhibit in vitro colony formation and in vivo tumour formation in animal studies [51]. In addition, hypermethylation of $\mathrm{p} 16$ has been detected in premalignant bronchial lesions, and this alteration is found more frequently in lesions demonstrating higher degrees of atypia [48]. The prevalence of hypermethylation of these genes in lung cancer varies with the most frequently affected genes being altered in just over one-half of lung cancers. Thus, taken alone, assays of hypermethylation of any of these genes would not demonstrate a high enough degree of sensitivity to be useful in lung cancer screening. However, recently published work by PALMISANO et al. [52] has demonstrated that by using a more sensitive assay for promoter hypermethylation to concomitantly assay p16 and MGMT genes, $100 \%$ of sputa specimens taken from patients with squamous cell carcinoma can be demonstrated to display aberrant methylation. Furthermore, these changes could be detected in sputa collected up to $3 \mathrm{yrs}$ before clinical diagnosis was established. Also of interest is the detection of p16 and MGMT gene hypermethylation in the serum of $75 \%$ of patients with the same changes in tumour tissue [53]. However, serum detection of p16 hypermethylation was found in only one of 10 patients with nonsmall cell lung cancer studied in a recent analysis [54]. Finally, treatment of cell lines demonstrating hypermethylation of the RAR- $\beta$ gene with demethylation agents has been shown to re-establish RAR- $\beta$ expression suggesting potential therapeutic applications [55].

\section{Specimens for clinical testing}

Most of the data discussed thus far regarding the early detection of lung cancer has concentrated on analysis of sputum specimens. However, other types of specimens have also been evaluated for their potential value in screening programmes. Serum samples have been utilized as sources for clinical testing in numerous disease processes and, due to the ease and low cost of collection, have also been studied extensively for their usefulness in establishing cancer diagnoses. Antibody, antigen and PCR based assays have been used to try to screen peripheral blood/ serum in patients with lung cancer. Studies aimed at identifying epithelial cell-related antigens in serum have been shown to lack adequate specificity [56, 57]. Recently, a study that attempted to identify autoantibodies to c-myc and circulating c-myc antigens in the serum of lung cancer patients showed a low level of sensitivity [58]. More promising results have been published regarding the detection of tumour specific DNA alterations in serum. Minute, but elevated levels of circulating DNA have been detected in cancer patients as compared to normal individuals [59-61]. Using PCR based assays microsatellite instability has been detected in the serum of $93 \%$ of patients with similar alterations in their small cell carcinomas [62]. As mentioned earlier, promising but unconfirmed findings regarding hypermethylation have also been reported in studies of serum from lung cancer patients [53].

Bronchoscopically obtained specimens have shown good potential as sources for molecular detection of lung cancer, although their value in screening analysis is tempered by the degree of invasiveness and cost associated with the procedure. Bronchoalveolar lavage (BAL) specimens obtained by re-aspirating saline infused into the airways of patients undergoing bronchoscopy should provide a specimen with a deeper epithelial component than found in sputum samples. Indeed, a recent study of BAL fluids revealed the detection of numerous tumour associated molecular alterations including frequent mutations in p53 and k-ras genes, and alterations in microsatellite loci and p16 promoter methylation status. Unfortunately, the sensitivity associated with the finding of these alterations was not as great as would ultimately be desired [63]. Similarly an analysis of p16 hypermethylation in BALs from a small group of patients with hypermethylated p16 gene in resected tumour tissue found a poor degree of sensitivity for detection in the corresponding BAL specimens [54]. Conversely, FIELDING et al. [64] demonstrated a high degree of sensitivity for detection of hnRNP A2/B1 overexpression in BAL specimens in patients with premalignant and malignant lung lesions. However, studies of BAL specimens have not demonstrated significant differences in comparisons to assays of sputa thus far. Bronchoscopically obtained biopsies have demonstrated a significantly increased sensitivity in detecting premalignant and early invasive lung lesions since the introduction of laser-induced fluorescence endoscopes (LIFE) [65]. Through this procedure dysplasias and early invasive bronchial lesions are identifiable as areas with decreased autoflourescence [66]. Using this technology experienced bronchoscopists can improve their sensitivity in detecting high-grade dysplasias and CIS by at least three-fold in comparison to white light bronchoscopy [65]. This improvement in sensitivity is associated with a slight but statistically significant decrease in specificity. The overall sensitivity for detecting these lesions by LIFE bronchoscopy is $\sim 70 \%$, and thus is not great enough to warrant routine employment of LIFE bronchoscopy in screening protocols. However, LIFE bronchoscopy will undoubtedly play an important role in validating proposed molecular screening assays and in verifying the presence of these high-risk lesions in patients identified through such screening procedures.

\section{Biomarkers for chemoprevention studies}

Chemoprevention studies in the lung are hampered by a lack of intermediate markers for treatment evaluation. Through the use of LIFE bronchoscopy it is now possible to diagnose preneoplastic lesions with a higher sensivity than previously [65]. The WHO system of classification for bronchial epithelial lesions includes eight morphological categories: normal, reserve cell hyperplasia, squamous metaplasia, mild, moderate and severe dysplasia, carcinoma in situ and invasive carcinoma. A study designed to validate 
this classification scheme evaluated interobserver variability between 10 internationally recognized pulmonary pathologists who independently classified a set of images of bronchial lesions distributed through the internet [67]. In addition to demonstrating that the distribution of internet images could be used to successfully evaluate interobserver variability, this study also clearly showed a high degree of interobserver agreement between pulmonary pathology experts in employing this classification of bronchial epithelial lesions. An interclass coefficient of 0.90 was found in this analysis (F.R. Hirsch, University of Colarado Helath Sciences Centre, Denver, CO, USA, personal communication).

An analysis of lesions in a high-risk cohort of subjects (patients with a diagnosis of chronic obstructive pulmonary disease and a smoking history $>30$ packyrs) found a difference in baseline morphological changes between former smokers and current smokers. Former smokers were found to have a lower level of dysplastic changes than current smokers [68]. An ongoing University of Colorado Cancer Center study of repeat bronchial biopsies taken from the same site as previously diagnosed bronchial lesions is being performed to validate the role of histological and immunohistochemical analyses as intermediate biomarkers for the evaluation of chemopreventive studies. Preliminary data have shown a statistical correlation between histological changes in the bronchial epithelium and the expression of markers such as Ki67, MCM2 and p53 [68]. This study is evaluating three models for the detection of changes in preneoplastic disease between initial and follow-up bronchoscopies: 1) changes in worst-to-worst diagnoses (i.e. the histological diagnosis in initial versus repeat bronchoscopy, respectively); 2) changes in average score of biopsy diagnoses (i.e. a diagnostic score based on a calculated average for a set of biopsies is compared between initial and repeat bronchoscopies); 3) changes in dysplasia index (i.e. fraction of biopsies with any degree of dysplasia as related to total number of biopsies taken at each bronchoscopy). Hopefully such studies will lead to a definition of a response model that can be used as an intermediate end-point in the evaluation of studies of chemopreventive agents.

To conclude, recent advances in the understanding of the molecular biology of premalignant and early invasive lung lesions has helped identify many promising potential markers of early lesions which will lead to new effective screening assays in high-risk populations. Using these assays in conjunction with advances in the radiographical detection of early lung cancer should further improve the ability to detect lung cancer prior to the development of advanced stage disease. By identifying these precursors and early invasive lesions in patients at high risk for the development of primary and secondary lung cancers it should ultimately be possible to reduce the overall mortality associated with lung cancer. Efficacious therapeutic options will be needed to achieve this reduction in the toll associated with this disease. Biomarkers will also be invaluable in evaluating potential treatments for preventing the progression of premalignant and malignant lung lesions. Clinical trials are being planned and are currently underway to evaluate these newly identified diagnostic and therapeutic approaches, and the results are being eagerly awaited.

\section{References}

1. Greenlee RT, Hill-Harmon MB, Murray T, Thun M. Cancer Statistics, 2001. CA Cancer J Clin 2001; 51: $15-36$.

2. Ihde DC. Chemotherapy of lung cancer. N Engl J Med 1992; 327: 1434-1441.

3. Mountain CT. Revision in the international system for staging of lung cancer. Chest 1997; 111: 1710-1717.

4. Melamed MR, Flehinger BJ, Zaman MB, Heelan RT, Parchick WA, Martini N. Screening for lung cancer: results of the Mermorial Sloan-Kettering study New York. Chest 1984; 86: 44-53.

5. Fontana RS, Sanderson DR, Woolner LB, Taylor WF, Miller WE, Muhm JR. Lung Cancer Screening. The Mayo program. J Occup Med 1986; 28: 746-750.

6. Tockman MS. Survival and mortality from lung cancer in a screened population: The John Hopkins Study. Chest 1986; 89: 324S-325S.

7. Saccomano G, Archer VE, Auerbach O, Saunders RP, Brennan LM. Development of carcinoma of the lung as reflected in exfoliated cells. Cancer (Phila) 1974; 32: 256-270.

8. Henschke CI, Miettinen OS, Yankelevitz DF, Libby DM, Smith JP. Radiographic screening for cancer: proposed paradigm for requisite research. Clin Imaging 1994; 18: 6-20.

9. Hirsch FR, Franklin WA, Gazdar AF, Bunn PA Jr. Early detection of lung cancer: clinical perspectives of recent advances and radiology. Clin Cancer Res 2001; 7: 5-22.

10. Auerbach O, Gere B, Forman JB, et al. Changes in bronchial epithelium in relation to smoking and cancer of the lung. N Engl J Med: 256: 97-104.

11. Wistuba II, Behrens C, Milchgrub S, et al. Sequential molecular abnormalities are involved in the multistage development of squamous cell lung carcinoma. Oncogene 1999; 18: 643-650.

12. Frost JK, Ball WC Jr, Levin ML, et al. Sputum cytopathology: use and potential in monitoring the workplace environment by screening for biological effects of exposure. J Occup Med 1986; 28: 692-703.

13. Venman BJW, van Boxem TJM, Smit EF, Postmus PE, Sutedja TG. Outcome of bronchial carcinoma in situ. Chest 2000; 117: 1572-1576.

14. Lam S, LeRiche JC, Zheng Y, et al. Sex-related differences in bronchial epithelial changes associated with tobacco smoking. J Natl Cancer Inst 1999; 91: 691-696.

15. Keith RL, Miller YE, Gemmill RM, et al. Angiogenic squamous dysplasia in bronchi of individuals at high risk for lung cancer. Clin Cancer Res 2000; 6: 16161625.

16. Muller KM, Muller G. The ultrastructure of preneoplastic changes in bronchial mucosa. Curr Top Pathol 1983; 73: 233-263.

17. Denhart BC, Guidi AJ, Tognazi K, Dvorak JF, Brown LF. Vascular permeability factor/vascular endothelial growth factor and its receptors in oral 
and laryngeal squamous cell carcinoma and dysplasia. Lab Invest 1997; 77: 659-664.

18. Fontanini G, Calcinai A, Boldrini L, et al. Modulation of neoangiogenesis in bronchial preneoplastic lesions. Oncol Rep 1999; 6: 813-817.

19. Boyle JO, Lonardo F, Chang JH, Klimstra D, Rusch $\mathrm{V}$, Dmitrovsky E. Multiple high-grade bronchial dysplasia and squamous cell carcinoma: concordant and discordant mutations. Clin Cancer Res 2001; 7: 259-266.

20. Slaughter DP, Southwick HW, Smejkal W. "Field cancerization" in oral stratified squamous epithelium. Clinical implications of multicentric origin. Cancer 1953; 6: 963-968.

21. Sozzi G, Miozzo M, Pastorino U, et al. Genetic evidence for an independent origin of multiple preneoplastic and neoplastic lung lesions. Cancer Res 1995; 55: 135-140.

22. Franklin WA, Gazdar AF, Haney J, et al. Widely dispersed $\mathrm{p} 53$ mutation in respiratory epithelium: a novel mechanism for field cancinogenesis. $J$ Clin Investig 1997; 100: 2133-2137.

23. Slebos RJ, Baas IO, Clement MJ, et al. P53 alterations in atypical alveolar hyperplasia of the human lung. Hum Pathol 1998; 29: 801-808.

24. Kitamura H, Kameda Y, Ito T, Hayashi H. Atypical adenomatous hyperplasia of the lung. Implications for the pathogenesis of perpheral lung adenocarcinoma. Am J Clin Pathol 1999; 111: 610-622.

25. Travis WD, Colby TB, Corrin B, Shimosato Y, Brambilla E. Histological typing of tumors of lung and pleura. In: Sobin LH, ed. World Health Organization International Classification of Tumours. 3rd edition. New York. Springer-Verlag, 1999.

26. Dai Y, Morishita Y, Mase K, et al. Application of the p53 and K-ras gene mutation patterns for cytologic diagnosis of recurrent lung carcinomas. Cancer 2000; 90: 258-263.

27. Chen JT, Ho WL, Cheng YW, Lee H. Detection of p53 mutations in sputum smears precedes diagnosis of nonsmall cell lung carcinoma. Anticancer Res 2000; 20: $2687-2690$.

28. Nishisaka T, TakeshimaY, Inai K. Evaluation of p53 gene mutation and loss of heterozygosity of $3 p, 9 p$ and $17 \mathrm{p}$ in precancerous lesions of 29 lung cancer patients. Hiroshima J Med Sci 200; 49: 109-116.

29. Brambilla E, Gazzeri S, Lantuehoul S, et al. p53 mutant immunophenotype and deregulation of p53 transcription pathway (Bcl 2, Bax, and Waf1) in precursor bronchial lesions of lung cancer. Clin Cancer Res 1998; 4: 1609-1618.

30. Wistuba II, Gazdar AF, Minna JD. Molecular genetics of small cell lung carcinoma. Semin Oncol 2001; 28: Suppl. 4, 3-13.

31. Hung J, Kishimoto Y, Sugio K, et al. Allele-specific chromosome $3 p$ deletions occur at an early stage in the pathogenesis of lung carcinoma. J Am Med Assoc 1995; 273: 558-563.

32. Kishimoto Y, Sugio K, Hung JY, et al. Allele-specific loss in chromosome 9p loci in preneoplastic lesions accompanying non-small cell lung cancers. $J$ Natl Cancer Inst 1995; 87: 1224-1229.

33. Sugio K, Kishimoto Y, Virmani AK, Hung JY, Gazdar AF. K-ras mutations are a relatively late event in the pathogenesis of lung carcinomas. Cancer Res 1994; 54: 5811-5815.

34. Wistuba II, Behrens C, Virmani AK, et al. Allelic losses at chromosome 8 p 21-23 are early and frequent events in the pathogenesis of lung cancer. Cancer Res 1999; 59: 1973-1979.

35. Kohno H, Hiroshima K, Toyozaki T, Fujisawa T, Ohwada H. p53 mutation and allelic loss of chromosome $3 \mathrm{p}, 9 \mathrm{p}$ of preneoplastic lesions in patients with nonsmall cell lung carcinoma. Cancer 1999; 85: 341347.

36. Hirano T, Franzen B, Kato H, Ebihara Y, Auer G. Genesis of squamus cell lung carcinoma: sequential changes of proliferation, DNA ploidy, and p53 expression. Am J Pathol 1994; 144: 296-302.

37. Betticher DC, Heighway J, Thatcher M, Hasleton PS. Abnormal expression of CCND1 and RB1 in resection margin epithelia of lung cancer patients. $\mathrm{Br} J$ Cancer 1997; 75: 1761-1768.

38. Satoh Y, Ishikawa $\mathrm{Y}$, Nakagawa $\mathrm{K}$, Hirano $\mathrm{T}$, Tsuchiya E. A follow-up study of progression from dysplasia to squamous cell carcinoma with immunohistochemical examination of p53 protein overexpression in the bronchi of ex-chromate worders. $\mathrm{Br}$ $J$ Cancer 1997; 75: 678-683.

39. Li Z, Zheng J, Weiss LM, Shibata D. c-k ras and p53 mutations occur very early in adenocarcinoma of the lung. Am J Pathol 1994; 144: 303-309.

40. Lonardo F, Rusch V, Langenfeld J, Dmitrovsky E, Klimstra DS. Overexpression of cyclins D1 and E is frequent in bronchial preneoplasia and precedes squamous cell carcinoma development. Cancer Res 1999; 59: 2470-2476.

41. Tan DF, Huberman JA, Hyland A, et al. MCM2 - a promising marker for premalignant lesions of the lung: a cohort study. BMC Cancer 2001; 1: 6.

42. Miozzo M, Sozzi G, Musso K, et al. Microsatellite alterations in bronchial and sputum specimens of lung cancer patients. Cancer Res 1996; 56: 2885-2888.

43. Vassilakis DA, Sourvinos G, Spandidos DA, Siafakas NM, Bouros D. Frequent genetic alterations at the microsatellite level in cytologic sputum samples of patients with idiopathic pulmonary fibrosis. $A m J$ Respir Crit Care Med 2000; 162: 1115-1119.

44. Tockman MS, Gupta PK, Myers JD, et al. Sensitive and specific monoclonal antibody recognition of human lung cancer antigen on preserved sputum cells: a new approach to early lung cancer detection. $J$ Clin Oncol 1988; 6: 1685-1693.

45. Zhou J, Mulshine JL, Unsworth EJ, et al. Purification and characterization of a protein that permits early detection of lung cancer. J Biol Chem 1996; 271: 10760-10766.

46. Sueoka E, Sueoka N, Goto Y, et al. Heterogenous nuclear ribonucleoprotein B1 as early cancer biomarker for occult cancer of human lungs and bronchial dysplasia. Cancer Res 2001; 61: 1896-1902.

47. Qiao Y-L, Tockman MS, Li L, et al. A case-cohort study of an early biomarker of lung cancer in a screening cohort of Yunnan tin miners in China. Cancer Epidemiol Biomark Prev 1997; 6: 893-900.

48. Belinsky SA, Nikula KJ, Palmisano WA, et al. Aberrant methylation of p16INK4a is an early event in lung cancer and a potential biomarker for early diagnosis. Proc Natl Acad Sci USA 1998; 95: 1189111896.

49. Zochbauer-Muller S, Fong KM, Virmani AK, Geradts J, Gazdar AF, Minna JD. Aberrant promoter methylation of multiple genes in non-small cell lung cancers. Cancer Res 2001; 61: 249-55. 
50. Zochbauer-Muller S, Fong KM, Maitra A, et al. 5' $\mathrm{CpG}$ island methylation of the FHIT gene is correlated with loss of gene expression in lung and breast cancer. Cancer Res 2001; 61: 3581-3585.

51. Burbee DG, Forgacs E, Zochbauer-Muller S, et al. Epigenetic inactivation of RASSF1A in lung and breast cancers and malignant phenotype suppression. J Natl Cancer Inst 2001; 93: 691-699.

52. Palmisano WA, Divine KK, Saccomanno G, et al. Predicting lung cancer by detecting aberrant promoter methylation in sputum. Cancer Res 2000; 60: 5954 5958.

53. Esteller M, Sanchez-Cespedes M, Rosell R, Sidransky D, Baylin SB, Herman JG. Detection of aberrant promoter hypermethylation of tumour suppressor genes in serum DNA from non-small cell lung cancer patients. Cancer Res 1999; 59: 67-70.

54. Kurakawa E, Shimamoto T, Utsumi K, Hirano T, Kato H, Ohyashiki K. Hypermethylation of p16(INK4a) and p15(INK4b) genes in non-small cell lung cancer. Int J Oncol 2001; 19: 277-281.

55. Virmani AK, Rathi A, Zochbauer-Muller S, et al. Promoter methylation and silencing of the retinoic acid receptor-beta gene in lung carcinomas. J Natl Cancer Inst 2000; 92: 1303-1307.

56. Pantel K, Schlimok G, Angstwurm M, et al. Methodological analysis of immunocytochemical screening for disseminated tumor cells in bone marrow. $J$ Hematother 1994; 3: 165-173.

57. Lanbrechts AC, Van't Veer LJ, Rodenhuis S. The detection of minimal numbers of contaminating epithelial tumor cells in blood or bone marrow: use, limitations and future of RNA-based methods. Ann Oncol 1998; 9: 1269-1276.

58. Yamamoto A, Shimizu E, Takeuchi E, et al. Infrequent presence of anti-v-Myc antibodies and absence of c-Myc oncoprotein in sera from lung cancer patients. Oncology 1999; 56: 129-133.

59. Leon SA, Shapiro B, Sklaroff DM, Yaros MJ. Free
DNA in the serum of cancer patients and the effect of therapy. Cancer Res 1977; 37: 646-650.

60. Stroun M, Anker P, Maurice P, Lyautey J, Lederrey C, Beljanski M. Neoplastic characteristics of the DNA found in the plasma of cancer patients. Oncology 1989; 46: 318-322.

61. Shapiro B, Chakrabaty M, CohnE SA, Leon A. Determination of circulating DNA levels in patients with benign or malignant gastrointestinal disease. Cancer (Phila) 1983; 51: 2116-2120.

62. Chen XQ, Stroun M, Magnenat J-L, et al. Microsatellite alterations in plasma DNA of small cell lung cancer patients. Nature Med 1996; 2: 1033-1037.

63. Arendt SA, Chow JT, Xu LH, et al. Molecular detection of tumor cells in bronchoalveolar lavage fluid from patients with early stage lung cancer. $J$ Natl Cancer Inst 1999; 91: 332-339.

64. Fielding P, Turnbull L, Prime W, Walshaw M, Field JK. Heterogeneous nuclear ribonucleoprotein A2/B1 up-regulation in bronchial lavage specimens: a clinical marker of early lung cancer detection. Clin Cancer Res 1999; 5: 4048-4052.

65. Hirsch FR, Prindiville SA, Miller YE, et al. Fluorescence versus white-light bronchoscopy for detection of preneoplastic lesions: a randomized study. J Natl Cancer Inst 2001; 93: 1385-1391.

66. Palcic B, Lam S, Hung J, MacAulay C. Detection and localization of early lung cancer by imaging techniques. Chest 1991; 99: 742-743.

67. Hirsch FR, Gazdar AF, Gabrielson E, Lam S, Franklin WA. A histopathologic evaluation of premalignant and early malignant bronchial lesions: an interactive program based on internet digital images to improve WHO criteria for early diagnosis of lung cancer and for monitoring chemoprevention studies - a SPORE collaborative project. Lung Cancer 2000; 29: 211.

68. Hirsch FR, Bunn PA Jr, Miller YE, et al. Intermediate biomarker profile for lung cancer chemoprevention trials. Proc Amer Soc Clin Oncology 2001; 20: 322. 